\title{
Synthesis and Protonation Constants of an Amide-Based Chelating Cyclophane
}

\author{
Julio Cesar Altamirano-Coronado ${ }^{\mathrm{a}}$, Carolina Godoy-Alcántar ${ }^{\mathrm{b}}$, Felipe Medrano ${ }^{\mathrm{a}}$ *
}

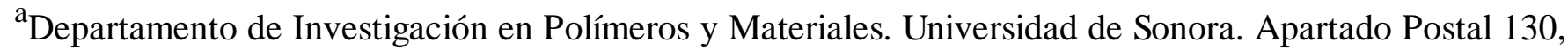
Col Centro.83000. Hermosillo, Sonora, México. Tel +52+662+2592161, Fax +52+662+592216.

email: fmedrano@polimeros.uson.mx, felipe.medrano@gmail.com

bCentro de Investigaciones Químicas, Universidad Autónoma del Estado de Morelos. 62209. Cuernavaca, Morelos, México. cga@uaem.mx

*Author to whom correspondence should be addressed

Received: 21 July 2006 / 29 September,2006 /Published:1 December 2006

Keywords: Cyclophane, potentiometry, protonation, amine, anhydride, condensation.

\section{Introduction}

Our research group have reported that, under high dilution conditions, condensation reactions between 4,4'-ethylenebis(2,6-morpholinedione), 1, and aromatic diamines gave a new series of tetraaza chelating cylophanes, which have amide and aromatic groups in the ring framework and pendant carboxymethyl groups [1]. The resulting functionalized macrocycles have novel coordination and structural properties due to the unique arrangement of different types of donor groups [2]. In this work, we have employed the aromatic diamine 1,3-bis(aminomethyl)benzene, 2, and obtained a new chelating cyclophane (3), 4,12,17,24-tetraoxo-6,9,19,22-tetrakis(carboxymethyl)-3,6,9,12,16,19,22,25-octaaza1,4(1,3)-dibenzacyclohexacosano .<smiles>O=C1CN(CCN2CC(=O)OC(=O)C2)CC(=O)O1</smiles>

1

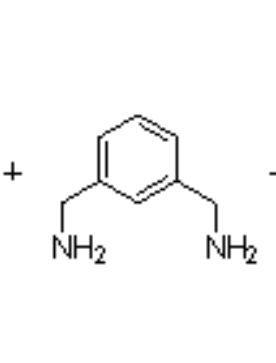

$\mathbf{2}$

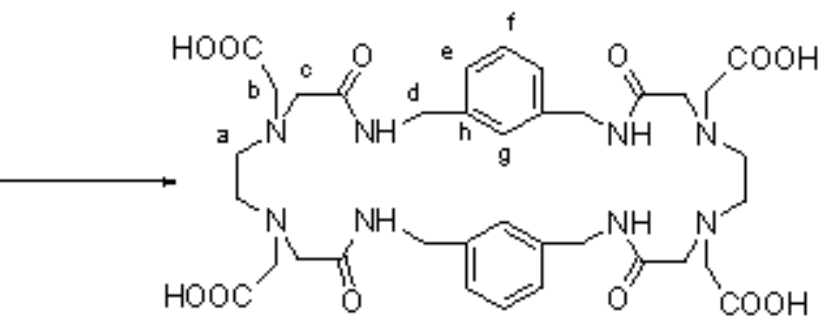

3

\section{Synthesis of 3}

Cyclophane $\mathbf{3}$ was obtained by the condensation reaction between $\mathbf{1}$ and $\mathbf{2}$ under high dilution conditions as was reported for other similar cyclophanes [1]. A dimethylformamide (DMF, Aldrich) solution (50 mL) containing $1 \mathrm{~g}$ of 1,3-bis(aminomethyl)benzene (Aldrich) was slowly added to $2.32 \mathrm{~g}$ of 4,4'-ethylenebis(2,6-morpholinedione) (Aldrich) in $250 \mathrm{~mL}$ of DMF with vigorous stirring during 2 hours. After the resulting reaction mixture was left to stand over night, any solid formed was removed by filtration and the filtrate was concentrated to a viscous liquid (ca. $10 \mathrm{~mL}$ ). Addition of ethanol (20 mL) to the liquid gave a pale yellow solid, which was separated by filtration. The crude solid was dissolved in 30 $\mathrm{mL}$ of boiling water. Cooling the resulting solution gave a colorless solid. The product was recovered by filtration, washed with water and dried under vacuum. Yield $15.3 \%$.

\section{Spectroscopic Measurements}

The solution electronic spectra were obtained by the use of a Perkin-Elmer Lambda 2 UV-vis spectrometer. The emission spectra were recorded on a Perkin Elmer LS-50 spectrofluorometer. The pH of the sample solutions was adjusted by adding a minimum amount of dilute $\mathrm{NaOH}$ solution or solid $\mathrm{Na}_{2} \mathrm{CO}_{3}$. The electrospray ionization (ESI) mass spectra were obtained by the use of a JEOL HX 110A 
spectrometer for sample solutions of an ammonia-methanol (5:95) mixture. The NMR spectra were obtained on a Bruker Avance 400 or Varian Unity 200 spectrometer in $\mathrm{D}_{2} \mathrm{O}$ with reference to sodium 2,2-dimethyl-2-silapentane-5-sulfonate, DSS. The infrared spectra were recorded on a Perkin-Elmer 1600 FT IR spectrophotometer and samples were analyzed as KBr pellets. The Elemental Analysis was performed by Centro de Investigaciones Químicas, Universidad Autónoma del Estado de Morelos. Cuernavaca, Mexico.

Anal. Calc. for $\mathrm{C}_{36} \mathrm{H}_{48} \mathrm{~N}_{8} \mathrm{O}_{12}\left(\mathrm{H}_{2} \mathrm{O}\right)_{3}$ : C,51.52; H,6.49; N, 13.36\%; found: C,51.67; H,6.48; N, 13.47\% .

$1_{\mathrm{H} \text { NMR (D2O-Na2 }} \mathrm{CO}_{3}$, pD 10.3, $400 \mathrm{MHz}$, reference DSS): $\mathrm{d}=7.29$ (t, 2H, $\left.\mathrm{H}_{\mathrm{f}}\right), 7.15$ (s, 2H, $\left.\mathrm{Hg}_{\mathrm{g}}\right), 7.13$ (d, 4H, $\mathrm{H}_{\mathrm{e}}$ ), 4.24 (s, 8H, $\mathrm{H}_{\mathrm{d}}$ ), 3.17 (s, 8H, He), 3.09 (s, 8H, $\left.\mathrm{H}_{\mathrm{b}}\right), 2.60$ (s, 8H, $\mathrm{H}_{\mathrm{a}}$ ).

${ }^{13} \mathrm{C}$ NMR ( $\mathrm{D}_{2} \mathrm{O}-\mathrm{Na}_{2} \mathrm{CO}_{3}, \mathrm{pD}$ 10.3, $50 \mathrm{MHz}$, reference $\left.\mathrm{DSS}\right): \mathrm{d}=179.17$ (-COO$\left.)^{-}\right), 174.14$ $(-\mathrm{CO}-\mathrm{NH}), 138.30\left(\mathrm{C}_{\mathrm{h}}\right), 129.32\left(\mathrm{Cg}_{\mathrm{g}}\right), 128.90\left(\mathrm{C}_{\mathrm{f}}\right), 126.76\left(\mathrm{C}_{\mathrm{e}}\right), 59.18\left(\mathrm{C}_{\mathrm{c}}\right), 58.43\left(\mathrm{C}_{\mathrm{b}}\right), 52.59\left(\mathrm{C}_{\mathrm{a}}\right), 42.85$ $\left(\mathrm{C}_{\mathrm{d}}\right)$.

IR: $3335 \mathrm{~cm}^{-1}$ (N-H, amide), $1728 \mathrm{~cm}^{-1}$ (C=O, Carboxylate), $1668 \mathrm{~cm}^{-1}$ (-CO-NH-, Amide I, ), $1641 \mathrm{~cm}^{-1}$ (-CO-NH-, Amide II), $798 \mathrm{~cm}^{-1}$ (aromatic), $709 \mathrm{~cm}^{-1}$ (aromatic).

UV (aqueous solution, pH 9.0 I = 0.1 M KCl): $260 \mathrm{~nm}\left(\mathrm{e}=510 \mathrm{M}^{-1} \mathrm{~cm}^{-1}\right)$.

Fluorescence (aqueous solution, pH 9.0, I = $0.1 \mathrm{M} \mathrm{KCl):} \mathrm{Emission} \mathrm{band} \mathrm{at} 290 \mathrm{~nm}$ (lexcitation = $260 \mathrm{~nm}$ ).

ESI MS: The electrospray mass spectrum of $\mathbf{3}$ in an ammoniacal methanol solution (Figure 1) exhibited, in addition to the $[\mathrm{M}+\mathrm{H}]^{+}$peak $(\mathrm{m} / \mathrm{z}=785.3,100 \%)$, an extra peak at $\mathrm{m} / \mathrm{z}=393.2(12 \%)[\mathrm{M}+2 \mathrm{H}]^{2+}$. The intervals between the isotope peaks proved that the latter species also had $z=2$.

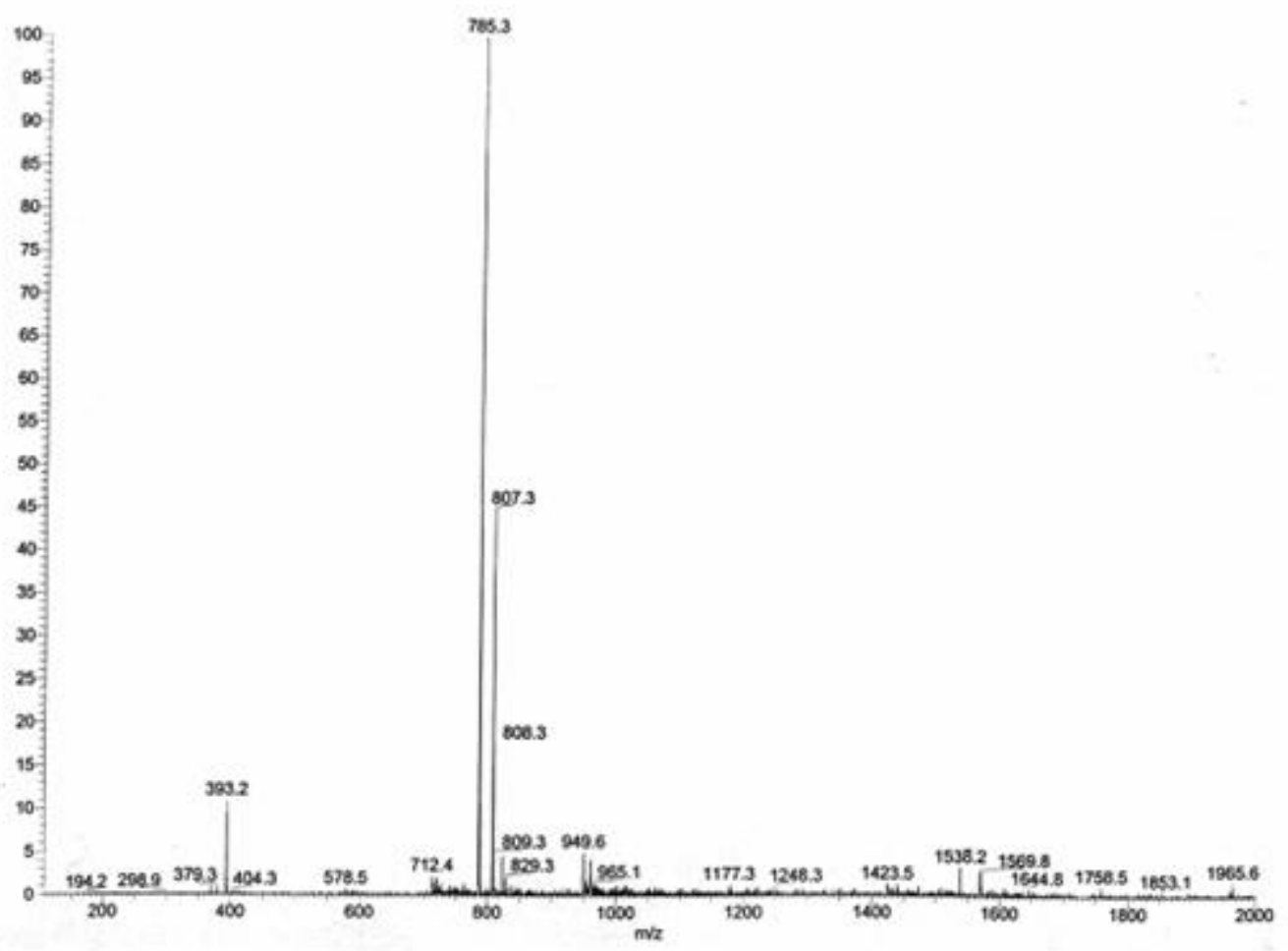

Figure 1. ESI mass spectrum of 3.

\section{Protonation Constants}

Coordination [2], molecular recognition [3], spectroscopic[1] and structural [4] properties of this class of compounds are strongly $\mathrm{pH}$ dependent, therefore the precise determination of their acidity constants is 
very important. The protonation constants of the cyclophane were determinated by potentiometry. The titrations were carried out at $298.1 \pm 0.1 \mathrm{~K}$ using $\mathrm{KCl} 0.1 \mathrm{M}$ as supporting electrolyte in a sealed-jacketed vessel under nitrogen with a piston type burette and a Thermo Orion model 920Aplus pHmeter equipped with an Orion 8102U combination electrode. The glass electrode was calibrated as a hydrogen-ion concentration probe by titration of previously standardized amounts of $\mathrm{HClO}_{4}$ with $\mathrm{CO}_{2}$-free $\mathrm{NaOH}$ solutions and determinated the equivalent point by Gran's method [5], which gives the ionic product of water (pKw = -13.95). The computer program HYPERQUAD 2000 [6] was used to calculate the protonation constants. The $\mathrm{pH}$ range investigated was $3-11$ and the concentration of macrocycle was $1 \mathrm{x}$ $10^{-3} \mathrm{M}$.

Only 4 protonation constants, of the eight expected, were detected as $\log \mathrm{K}_{1}=7.70$ (standard deviation = 0.06), $\log K_{2}=6.63$ (0.06), $\log K_{3}=3.91(0.09)$ and $\log K_{4}=3.34(0.10)$ and correspond to the stepwise basicity constants as described by the equilibrium equations:

$$
\begin{aligned}
& H_{n-1} L+H^{+} \rightarrow H_{n} L \\
& K_{n}=\frac{\left[H_{n} L\right]}{\left[H^{+}\right]\left[H_{n-1} L\right]}
\end{aligned}
$$

Distribution diagram of the various species present in solution was calculated using the program SPECIES (Academic Software) and is shown in Figure 2.

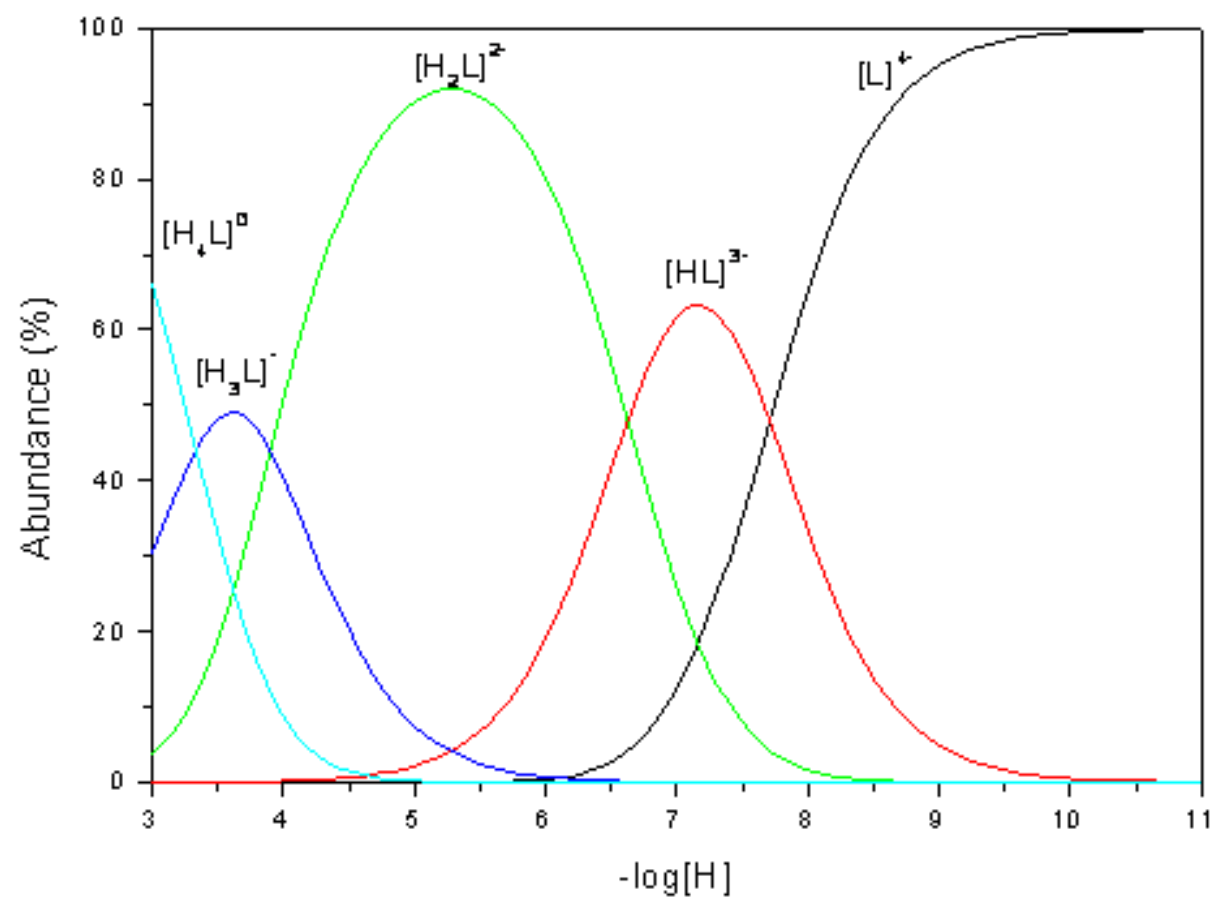

Figure 2. Calculated species distribution plots for $\mathbf{3 .}$

Based on the reported data for other similar cyclophanes [1,2] is possible to assign the observed constants: first and second protonation events occur at amine nitrogen atoms, while third and fourth protonations occur at carboxylate oxygen atoms.

\section{Acknowledgments}

The authors thank CONACyT for the financial support (grant 39574Q)

\section{References}

1. Inoue, M. B; Medrano, F; Inoue, M, and Fernando,Q. J. Chem. Soc. Perkin Trans. 2, 1998, 2275-2279.

2. Inoue, M. B; Medrano, F; Inoue, M; Raitsimiring, A. and Fernando, Q. Inorg.Chem., 1997,36, 2335-2340.

3. Virues, C.; Velazquez, E. F.; Inoue, M. B. and M. Inoue, J. Inclusion Phenom. and Macrocyclic Chem., 
2004, 48, 141-146.

4. Altamirano-Coronado, J.C; Hopfl, H; Godoy-Alcantar, C; Machi, L and Medrano. F. Analytical Sciences: $X$-ray structure on line. 2006. in press.

5. Martell, A.E. and Motekaitis. Determination and use of stability constants. Wiley-VCH: New York, 1992; pp 37-40.

6. Gans, P; Sabatini, A. and Vacca, A. Talanta, 1996, 43, 1739-1753.

2006 MDPI. All rights reserved. 